\title{
Pearlite Spheroidization Mechanism and Lifetime Prediction of 12Cr1MoV Steel used in Power Plant
}

\author{
Qiu-Hong ZHAO ${ }^{1, a}$, Bin JIANG ${ }^{1, b}$, Jia-Mei WANG ${ }^{2, c,{ }^{*}}$ \\ ${ }^{1}$ Tianjin special equipment inspection institute, Tianjin \\ ${ }^{2}$ Tianjin University School of Material Science and Engineering, Tianjin \\ ab.jiang@aliyun.com, bjiang_binsg@aliyun.com, cwjm8070@163.com \\ ${ }^{\star}$ Corresponding author
}

Key word: Pearlite spheroidization, 12Cr1MoV, Hardness, Life prediction.

\begin{abstract}
High temperature aging method was used to accelerate the aging process of $12 \mathrm{Cr} 1 \mathrm{MoV}$ steel which is mainly used as pressure vessel, steam pipes and so on. The evolution of the microstructure and mechanical property was systematically investigated during the process. It is revealed that during the aging process, pearlite was spheroidized gradually and carbide gathered at the grain boundary. The rate of pearlite spheroidization gradually reduced with the high temperature aging time increasing. Based on the hardness measurement and the analysis of the microstructure, the service life of the material was predicted through the combination of the hardness value and the Larson-Miller parameters.
\end{abstract}

\section{Introduction}

$12 \mathrm{Cr} 1 \mathrm{MoV}$ steel is widely used as boiler superheater, steel box and main steam pipes under high pressure, super high pressure and subcritical pressure [1-4]. With high oxidation resistance and thermal strength, the creep limit of $12 \mathrm{Cr} 1 \mathrm{MoV}$ steel is very close to the strength value with high plasticity in the case of long lasting tension. $12 \mathrm{Cr} 1 \mathrm{MoV}$ steel has high hot strength and oxidation resistance and high durable plastic even at $580^{\circ} \mathrm{C}$. In addition, the processing and welding property of the steel are well. However, in the long-term use at $580^{\circ} \mathrm{C}$, the pearlite in the microstructure of steels will be spheroidized, that is, the shape of the $\mathrm{Fe}_{3} \mathrm{C}$ in the pearlite gradually transforms into granular carbide, mainly including the fracture of the lamellar structure and grain coarsening [5]. In addition to the structural defects of itself, there are other factors affecting the rate of the spheroidization, such as pearlite spacing and alloying elements, which can not be ignored [6,7]. With the increase of pearlite spheroidization and the dilution degree of alloying elements in solid solution, mechanical properties of the steel decrease gradually resulting in material deterioration even failure [8,9].

For the power station boiler steel [10], the life of the steel materials is usually predicted through the combination of the non destructive testing (NDT) and Larson-Miller parameter (LMP) formula [11-13]. Hardness indicates not only the ability of the material to resist deformation, but also the damage of the material in the long term. There is relationship between the hardness tests and creep resistance [14]. H.C. Furtado [15]studied the relationship between hardness and LMP of the 9Cr-Mo ferrite steel and found a method to evaluate the injury degree of the material based on hardness test. The formula HV=961.713-0.020669P was used to describe the relationship between the hardness and LMP[16]. Therefore, the remaining service life of the material can be obtained by the change of hardness data, when the temperature and pressure are known. However, the microstructure imparity at different regions of materials may lead to abnormal value of material hardness. In order to well characterize the damage of material, hardness measurement and microstructure observation should be both considered. Thus, it is very important to investigate the relationship between the microstructure and hardness to predict the remaining service life of $12 \mathrm{Cr} 1 \mathrm{MoV}$ steel. In this paper, we systematically investigated the microstructure and hardness of $12 \mathrm{Cr} 1 \mathrm{MoV}$ steel during different aging processes. Together with the microstructure characterization, the service life of the steel is predicted based on the analysis of the material hardness. 


\section{Experimental Materials and Methods}

The material is the new tube without use provided by the Tianjin special inspection institute. The composition of the material was detected by ARL4460 spectrometer and HX-HW8B carbon sulfur detection instrument. Components were as follows: 0.119C, $0.232 \mathrm{Si}, 0.6 \mathrm{Mn}, 1.02 \mathrm{Cr}, 0.264 \mathrm{Mo}$, $0.011 \mathrm{Cu}$ and a very small amount of $\mathrm{P}$ and $\mathrm{S}$, and the residual component is Fe.

In order to investigate the influence of temperature and aging time on the spheroidization degree of $12 \mathrm{Cr} 1 \mathrm{MoV}$, the samples were heated at different temperature and aging time. $12 \mathrm{Cr} 1 \mathrm{MoV}$ was put into the resistance furnace for the aging heat treatment. The aging time was set as from 2 to $168 \mathrm{~h}$ at $500,550,600$, and $650^{\circ} \mathrm{C}$, respectively. Then the specimen was moved out under the air cooling.

The microstructure and morphology of the materials were characterized by OLYMPUS BX41M optical microscope, S4800 scanning electron microscope, and SU1510 scanning electron microscope. According to the national standard, the spheroidization degree of $12 \mathrm{Cr} 1 \mathrm{MoV}$ is divided into 5 levels: non-spheroidization (level 1), mild spheroidization (level 2), moderate spheroidization (level 3), complete (level 4) and serious (level 5) spheroidization. Level 1: pearlite (bainite) region is obvious, the carbide in pearlite is not all of the lamellar, and there is a gray block area. Level 2: the aggregation morphology of the pearlite region has begun to disperse. But its composition is still relatively compact, and the pearlite maintains the original shape of the region. Level 3: the carbide in pearlite region has been significantly dispersed and transferred into small balls, but the original shape of the region still maintains. Level 4: most of the carbide has been dispersed in the ferrite grain boundaries, and there is only trace of pearlite region. Level 5: pearlite regional morphology has completely disappeared, and carbide particles are distributed in the ferrite grain boundaries with dimorphism.

Vickers hardness (HV) test was done through the HMV-1000TMB video display automatic rotating tower microhardness tester with the test loading of $50 \mathrm{~g}$ and loading time of $5 \mathrm{~s}$, and the pressure head was regular pyramid type diamond indenter.

\section{Results and Discussion}

Figure 2 shows the metallographic images of the $12 \mathrm{Cr} 1 \mathrm{MoV}$ specimens heat-treated at 550, 600, and $650^{\circ} \mathrm{C}$ for 32, 118, $168 \mathrm{~h}$, respectively. In the initial state (Fig.1), the specimen contains black and white phases. The white phase is ferrite as the matrix of material, and the black region is the pearlite phase. Because the content of carbon in the sample is low, the pearlite is evenly distributed in the matrix, which is mainly located at the intersection of the grain boundary and the grain boundary.

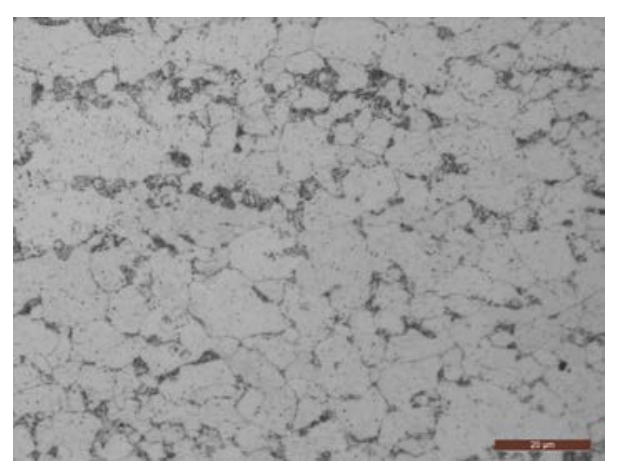

Fig.1, Metallographic images of the initial samples

Compared with the initial microstructure, there is no obvious difference of the distribution of pearlite in the specimens heat-treated for seven days (168h) at $550{ }^{\circ} \mathrm{C}$. According to the law of diffusion, the diffusion of carbon needs to reach certain diffusion activation energy. The holding temperature of $550{ }^{\circ} \mathrm{C}$ is low and close to the actual working temperature. With shorter aging time compared with the actual working time of the steel, there is no apparent diffusion carbon, and thus, 
the morphology of the pearlite changes little in Fig.2 (a.b.c). In contrast, after heat treated at $600{ }^{\circ} \mathrm{C}$ for $168 \mathrm{~h}$, pearlite zone is reduced, and the distribution density of carbides decreases and becomes sparse in Fig.2f. Since the temperature has a significant impact on the diffusion of atoms in the materials, under the same holding time, with the temperature increasing by $50{ }^{\circ} \mathrm{C}$, atomic thermal motion of carbon increases. Thus, the diffusion coefficient of carbon increases significantly, and the diffusion rate becomes fast. As a result, pearlite spheroidization is obvious. When the temperature further increases to $650^{\circ} \mathrm{C}$, pearlite area and distribution density of carbides obviously decrease after only $32 \mathrm{~h}$ heat treatment in Fig.2g. With the holding time increasing to $118 \mathrm{~h}$, the pearlite area almost disappears. Carbides distributes at the grain boundaries with only a small amount of carbides distributing in the original pearlite area in Fig.2h. With the holding time further increasing, carbide gathers at the grain boundaries, and there is large granular carbides in Fig.2i.
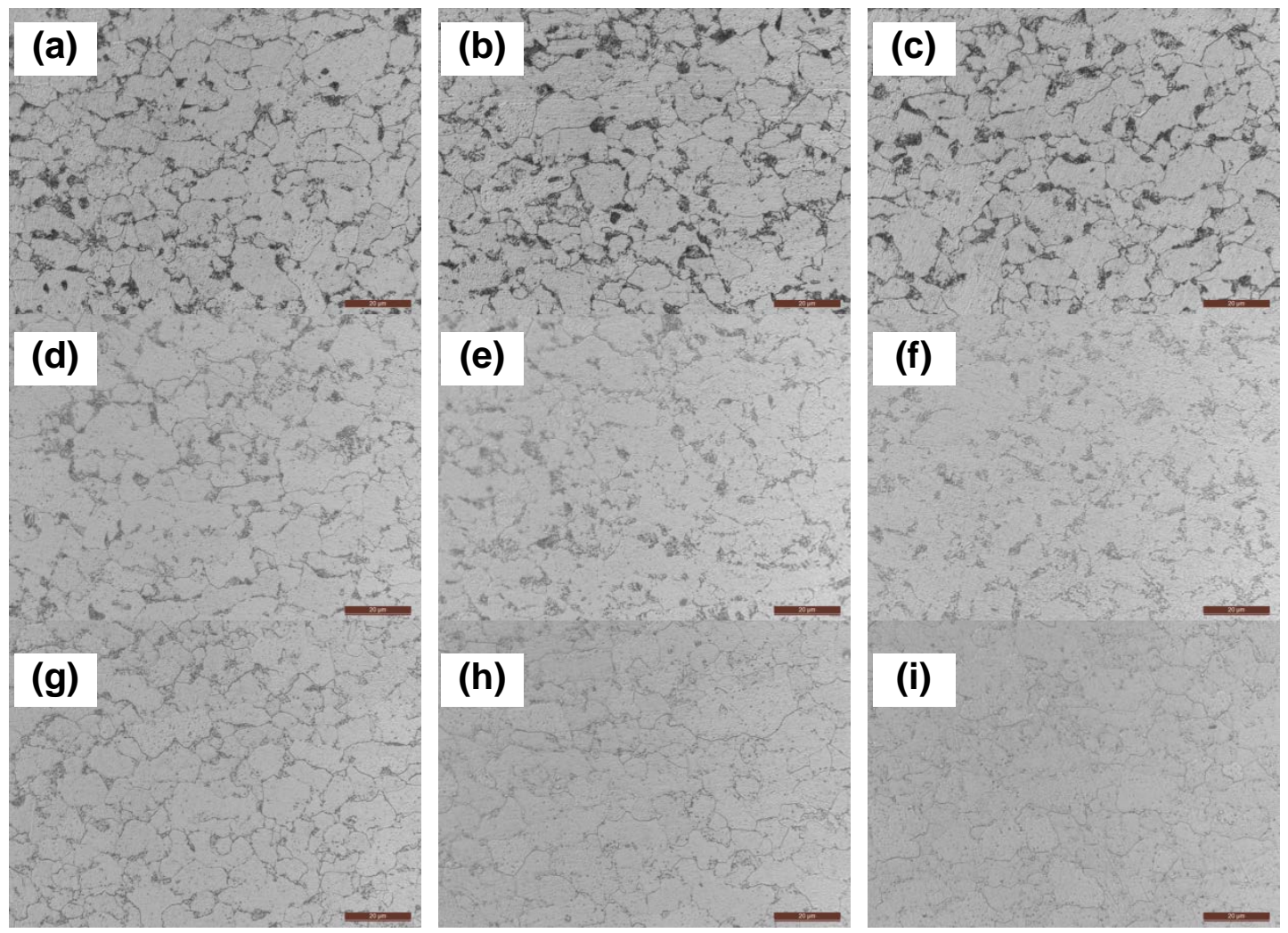

Fig.2, Metallographic images of the samples heat-treated at different temperature and time.
(a) $550^{\circ} \mathrm{C}$
C, 32 h; (b)
(b) $550^{\circ} \mathrm{C}, 118 \mathrm{~h}$;
(c) $550^{\circ} \mathrm{C}$
C, $168 \mathrm{~h} ;(\mathrm{d})$
(d) $600{ }^{\circ} \mathrm{C}$
C, 32 h; $(\mathrm{e})$ $168 \mathrm{~h} ;(\mathrm{g}) 650^{\circ} \mathrm{C}, 32 \mathrm{~h}$; (h)
(h) $650^{\circ} \mathrm{C}, 118 \mathrm{~h}$;
(i) $650^{\circ} \mathrm{C}, 168 \mathrm{~h}$.

The microstructures of the samples were further analyzed by scanning electron microscope, as shown in Fig.3. Metallographic images of the samples reveal no obvious change at $550^{\circ} \mathrm{C}$. More detailed observation through SEM images shows that the pearlite undergoes significant changes. With the holding time of 38h, the lamellar structure significantly reduces (Fig.3a). There is short rod and little granular carbide. Thus, the pearlite spheroidization begins, namely mild spheroidization (level 2). With the holding time increasing to 118h, the pearlite lamellar structure gradually disappears, showing more short rod and granular carbide, and the amount and area of the pearlite distribution decreases (Fig.3b). When the heat treatment lasts 168h, the carbide distributes in the long strip near the grain boundary, and the carbide at the grain boundary increases. The pearlite spheroidization stage is between the level 2 and 3 (Fig.3c).

The microstructure of the specimen heat treated at $600{ }^{\circ} \mathrm{C}$ for $38 \mathrm{~h}$ exhibits that the pearlite lamellar structure completely disappears with the short rod and granular carbide distributing in the original pearlite region(Fig.3d). The microstructure is similar to that of the sample heat treated at $550^{\circ} \mathrm{C}$ for $168 \mathrm{~h}$, confirming the significant impact of holding temperature on the diffusion of carbon. 
With the holding time increasing, short rod carbide gradually changes into a small ball, which still distributes in the original pearlite region (Fig.3e). The spheroidization stage enters into the moderate stage (level 3). When the holding time reaches $168 \mathrm{~h}$, the distribution of carbide (white phase) significantly reduces, and the size of carbide particle decreases in the matrix (Fig.3f). The carbide begins to increase at the grain boundary, forming a larger carbide particles.

The samples were subjected to heat treatment for different time at $650^{\circ} \mathrm{C}$. With the holding time of 38h, the pearlite spheroidization stage has reached level 3, and carbide obviously distributes at the grain boundary (Fig.3g). With the holding time prolonged to 118h, the content of carbide in the matrix decreases significantly, and most of the carbide distribution in the ferrite grain boundaries (Fig.3h). There is only trace of pearlite region, indicating the complete spheroidization (level 4). After heat treated at $650^{\circ} \mathrm{C}$ for $168 \mathrm{~h}$, the morphology of the pearlite has been completely disappeared, and the carbide particles distribute on the ferrite grain boundaries (Fig.3i), exhibiting serious spheroidization (near level 5).
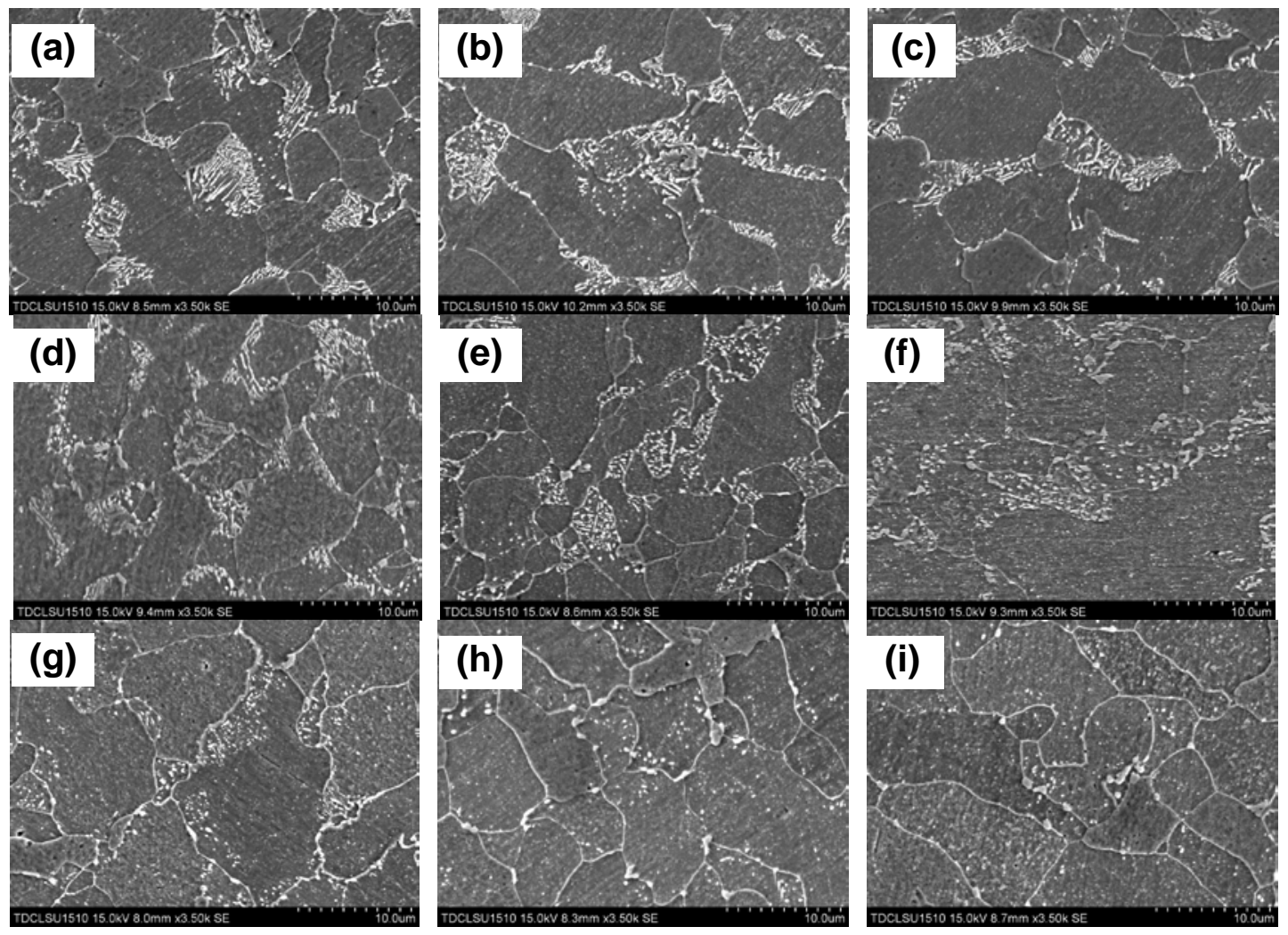

Fig.3, SEM images of the samples heat-treated at different temperature for different time. (a) $550{ }^{\circ} \mathrm{C}, 32 \mathrm{~h}$; (b) $550{ }^{\circ} \mathrm{C}, 118 \mathrm{~h}$; (c) $550{ }^{\circ} \mathrm{C}, 168 \mathrm{~h}$; (d) $600{ }^{\circ} \mathrm{C}, 32 \mathrm{~h}$; (e) $600{ }^{\circ} \mathrm{C}, 118 \mathrm{~h}$; (f) $600^{\circ} \mathrm{C}$, $168 \mathrm{~h}$; (g) $650{ }^{\circ} \mathrm{C}, 32 \mathrm{~h}$; (h) $650{ }^{\circ} \mathrm{C}, 118 \mathrm{~h}$; (i) $650{ }^{\circ} \mathrm{C}, 168 \mathrm{~h}$.

Hardness test was carried out on the samples of $12 \mathrm{Cr} 1 \mathrm{MoV}$ material at different holding temperature $\left(550,600,650^{\circ} \mathrm{C}\right)$ for different time. As shown in Fig.4, during the heat treatment at different holding temperature, the hardness value of the samples decreases significantly at first. Then, the hardness value maintains a relatively stable stage. When the holding time exceeds a certain value, the hardness decreases dramatically again. When the holding temperature is $550^{\circ} \mathrm{C}$, the hardness fluctuates between 150-160HV with the holding time increasing. When the holding time is more than 50h, the hardness declines slowly with the holding time increasing. With the holding time up to $168 \mathrm{~h}$, the hardness value appears a substantial decline and reaches the minimum value of $140.1 \mathrm{HV}$. When the holding temperature is $600^{\circ} \mathrm{C}$, the hardness value of the sample also decreases with holding time increasing, and there is a significant decrease of the hardness value at $168 \mathrm{~h}$. With the holding temperature increasing to $650^{\circ} \mathrm{C}$, the hardness value of the sample decreases sharply with the increase of the holding time. When the holding time reaches 20h, the hardness 
value appears a small range of fluctuation, which is basically stable at $130-135 \mathrm{HV}$.

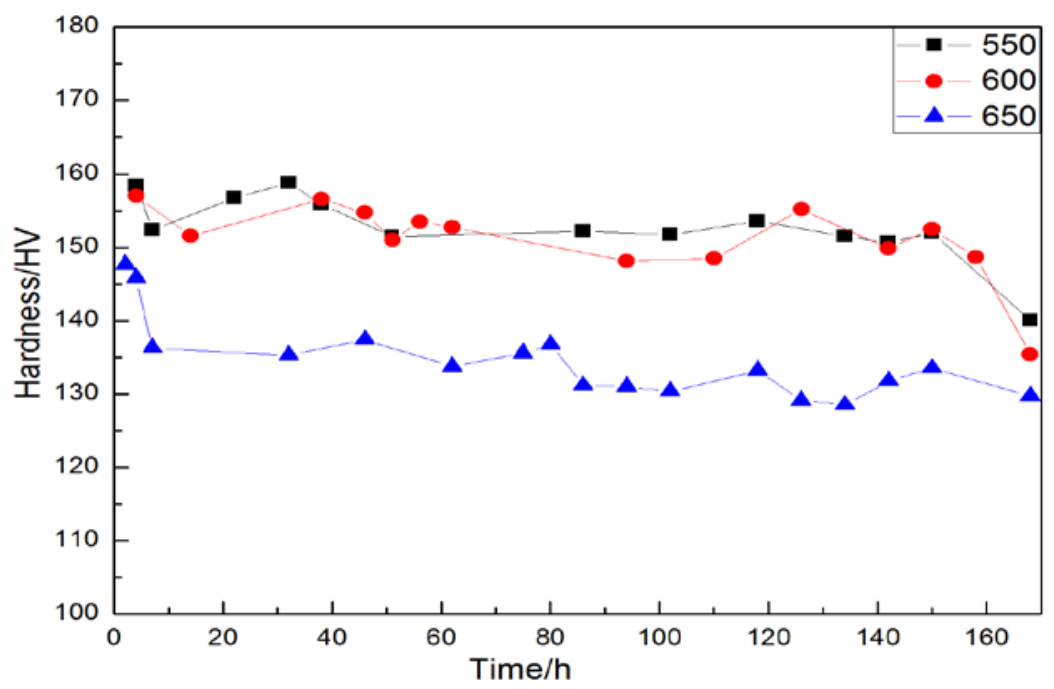

Fig.4, The hardness changes with the holding time of the samples heat-treated at different temperature.

With the morphology changes of the samples under consideration, the hardness is related to the content and shape of carbide of the samples. With the increase of the heat holding time, carbide decreases and aggregates, and then the strength of materials decreases. Thus, the hardness value also falls. After the pearlite is completely spheroidized, the formation of carbide particles and the related diffusion have little effects on the hardness value.

With increase of aging temperature and holding time, the hardness values decreased. At the beginning, the hardness values slowed down. When the time reached $150 \mathrm{~h}$, it decreased dramatically. This is because that during the heating and heat preservation process, the shape of carbide transformed from the original lamellar structure to the granular, or even disappeared, namely the spheroidizing phenomenon. At the same time its content decreased gradually, so the material hardness values decreased. However, the means of only hardness value to predict the change tendency of the material will has great error. Because in the process of heat preservation, materials is not uniform. Heating temperature deviation, its own defects and other reasons will increase inaccuracy of hardness testing. Therefore, we combine the observation of microstructure with hardness values, to eliminate the unreasonable hardness test values, increasing the accuracy of the experiment, and improving the reliability of the material life prediction.

Hardness is the characterization of the strength of materials and the macroscopical embodiment of mechanical properties of materials. Spheroidization degree is the characterization of the microstructure deterioration of Cr-Mn steels. When the spheroidization degree is deeper, the hardness decreases correspondingly. Thus, the mechanical property of the material deteriorates more seriously, and the remaining life would be less. It is important but difficult to predict conveniently and effectively the remaining life of the furnace tube in boiler inspection. Therefore, the establishment of the relationship between hardness and the pearlite spheroidization degree is particularly important, in order to find a new life evaluation method. Thus we choose the $130 \mathrm{HV}$ as the hardness at level 5, when predicting the life of samples.

Pan Boding et.al [17] proposed one life assessment method based on Vickers hardness data. According to the relationship $\mathrm{H}=\mathrm{f}$ (LMP)between the Vickers hardness and the spheroidization time and temperature, the actual life of the material at a certain temperature can be obtained. $\mathrm{LMP}=\mathrm{T}(20+\lg \mathrm{t}) * 10^{-3}$, where $\mathrm{T}$ is the holding temperature, and unit is $\mathrm{K} ; \mathrm{t}$ is the use time, and unit is h. As shown in Fig.5, a linear relationship between H and LMP is revealed, consistent with previous reports [14-17]. Thus, the relationship between $\mathrm{H}$ and LMP can be expressed as $\mathrm{HV}=\mathrm{A}$ B*LMP, where A and B are constants which can be determined through data fitting. The fitting lines 
are shown in Fig.5.

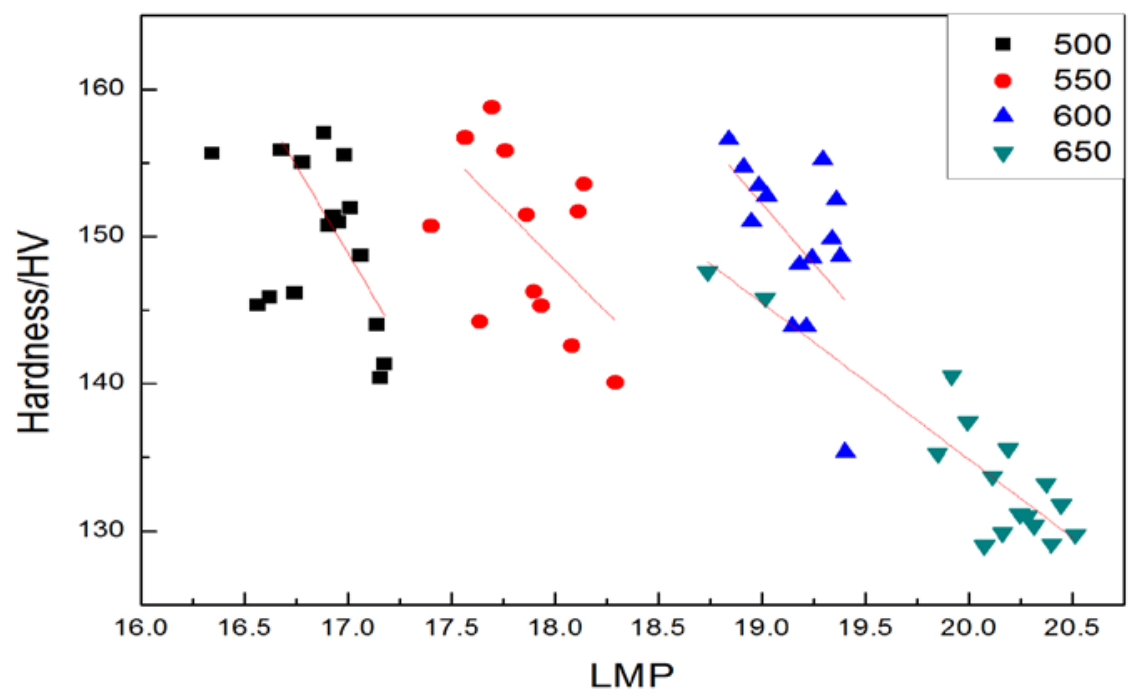

Fig.5, The relationship between the hardness and LMP of the samples under different conditions

According to the requirements of pipeline in thermal power plant and national counterparts of China, the material is disabled when hardness value reaches $130 \mathrm{HV}$. Then the service life can be predicted.

The fitting results of the above four curves are as follows:

(1) $500^{\circ} \mathrm{C} \mathrm{HV}=589.585-23.748 \mathrm{LMP} \quad$ when $\mathrm{HV}=130, \mathrm{t}=10 \wedge 5.0357 \mathrm{~h}, 12.393 y e a r s$.

(2) $550^{\circ} \mathrm{C} H V=461.658-16.285 \mathrm{LMP} \quad$ when $\mathrm{HV}=130, \mathrm{t}=10^{\wedge} 3.3286 \mathrm{~h}, 2131.027 \mathrm{~h}$.

(3) $600^{\circ} \mathrm{C} \mathrm{HV}=402.372-14.110 \mathrm{LMP} \quad$ when $\mathrm{HV}=130, \mathrm{t}=10 \wedge 53.1106 \mathrm{~h}, 1289.894 \mathrm{~h}$.

(4) $650^{\circ} \mathrm{CHV}=347.283-10.621 \mathrm{LMP} \quad$ when $\mathrm{HV}=130, \mathrm{t}=10 \wedge 2.1645 \mathrm{~h}, 146.061 \mathrm{~h}$.

Based on the above discussion, working temperature has significant effect on the life time of the Cr-Mo steel. With the increase of holding temperature, life time is shortened sharply. Therefore, in industrial production, the Cr-Mo steel should be avoided to be used in the situation of overheating, and the industrial production order should be strictly complied with. In order to take timely and effective measures to avoid the production and huge economic losses brought by the material serious spheroidization, material microstructure and hardness value should be characterized periodically. The method, namely reliable Vickers hardness test together with microstructure characterization, then the predication of the service life by establishing the relation between the hardness and LMP, may be extended to predict use life of the pressure parts of power plant boiler. Other materials of boiler pressure parts can also establish the relationship between Vickers hardness and the use time and temperature such as 15CrMoG, 20G, T91et.al.

\section{Summary}

The microstructure and hardness of $12 \mathrm{Cr} 1 \mathrm{MoV}$ steel with the heat treatment temperature and time is systematically studied, and the life prediction was carried out based on hardness test. It is revealed that: (1)At a certain temperature, with the increase of the holding time, the lamellar structure of pearlite disappeared and the pearlite was spheroidized. Carbide was gradually distributed at the grain boundary. And the temperature had a significant effect on the pearlite spheroidization. (2) The hardness value decreases with the increase of the holding time, due to the disappearance of the lamellar structure and the reduction of the carbide. (3) Combined with the microstructure analysis and hardness measurement, the life assessment formula at different temperature is obtained. In the actual production, there are corrosion, oxidation, overheating and other factors on the material, which have a great influence on use of life. Therefore, we should periodically detect and record on the material, to ensure the usage status and avoid huge losses. 


\section{Acknowledgement}

This research was financially supported by the Tianjin special equipment inspection institute.

\section{References}

[1]Zheng-Hong GUO. Research progress on the mechanism of pearlite transformation in steel [J]. Journal of heat treatment of materials, 2003, 24 (3): 1-7.

[2]Shun-Shen ZHOU. Evaluation of residual life of high temperature components in thermal power plant [M]. Beijing: China Electric Power Press, 2006.

[3]Yi-You TU, Xiang-Liang LIU, Jian-Qing JIANG, et al. Effect of annealing process on microstructure and properties of high strength plastic deformation pearlite steel wire [J]. Journal of heat treatment, 2006, 27 (5): 43-45.

[4]Zhu-Li HE. Failure analysis and residual life prediction of power plant boiler superheater tube[J].Journal of Changsha Railway, 2003, 21 (1): 108 -112.

[5]SAHA A, MONDAL D K, MAITY J. Effect of cyclic heat treatment on microstructure and mechanical properties of $0.6 \mathrm{wt} \%$ carbon steel [J]. Materials Science and Engineering: A, 2010, 527(16): 4001-4007.

[6]MARDER A R, et al. Met. Trans., 1976, 7A:1801

[7]YI H L, HOU Z Y, XU Y B, et al. Acceleration of spheroidization in eutectoid steels by the addition of aluminum[J]. Scripta Materialia, 2012, 67(7): 645-648.

[8]Wan-Fu GAO. The effect of the spheroidization on mechanical properties of 15CrMo pearlite steel [J]. Journal of petrochemical colleges and Universities, 1997, 10 (4): 40-43.

[9]RAY A K, SAHAY S K, GOSWAMI B. Assessment of service exposed boiler tubes[J]. Engineering Failure Analysis, 2003, 10(6): 645-654.

[10]LARSON F R, MILLER J. A time-temperature relationship for rupture and creep stresses[M]. 1952.

[11]LIM J H, KOH J S. Reliability analysis and comparison of several structures[J]. Microelectronics Reliability, 1997, 37(4): 653-660.

[12]FOSCHI R O. Reliability theory and applications to risk analysis of power components and systems[J]. International journal of electrical power \& energy systems, 2004, 26(4): 249-256.

[13]VISWANATHAN R, DOOLEY R, SAXENA A. In Proceedings of International Conference on Life Assessment and Extension, Vol. 2, Congress Centre The Hague/The Netherlands. 1988. p. 175.

[14]KOHLHOFER W, PENNY R K. Hardness testing as a means for creep assessment[J]. International journal of pressure vessels and piping, 1996, 66(1): 333-339.

[15]FURTADO H C, ROCHA R, MICHASKY M, et al. Evaluation of the integrity of power plant equipment based on inspection, monitoring and computational diagnosis[J]. OMMI Power Plant-Operation, Maintenance and Materials Issues, 2008, 5: 5-6.

[16]PURBOLAKSONO J, AHMAD J, KHINANI A, et al. Failure case studies of SA213-T22 steel tubes of boiler through computer simulations[J]. Journal of loss prevention in the process industries, 2010, 23(1): 98-105.

[17]Jin-Ping PAN, Bai-Ding PAN, Hong-Hui CHENG, et al. Study on the relationship between hardness and spheroidization and its service life evaluation of 12Cr1MoVG materials[J]. Journal of materials heat treatment technology, 2012, 33 (6): 125-130. 